\title{
Evidence of early and late diagenesis of sediments from past habitable environments in Gale crater, Mars: A Mastcam multispectral perspective
}

A. RUdOLPH ${ }^{1 *}$, J. HABER ${ }^{1}$, B. HORGAN ${ }^{1}, K$. BENNETT $^{2}$, V.FOX ${ }^{3}$, C. SEEGER ${ }^{4}$, M. RICE ${ }^{4}$, J.R. JOHNSON $^{5}$, J. F. BELL III' ${ }^{6}$, S. JACOB ${ }^{6}$, E. RAMPE

${ }^{1}$ Purdue University, West Lafayetee, IN 47907

(*correspondence: rudolph4@purdue.edu) ${ }^{2}$ USGS Astrogeology Science Center, Flagtaff, AZ 86011 ${ }^{3}$ California Institute of Technology, Pasadena, CA 91125 ${ }^{4}$ Western Washington University, Bellingham, WA 98225 ${ }^{5}$ JHU/Applied Physics Lab, Laurel, MD 20723 ${ }^{6}$ Arizona State University, Tempe, AZ 85281

${ }^{7}$ NASA/Johnson Space Center, Houston, TX 77058

The Curiosity rover is within an ancient fluviolacustrine environment in Mt. Sharp, Gale crater, Mars, that was habitable for early life [1]; however, the lacustrine sediments also show evidence of diagenesis. Determining if the rock properties reflect the original environment or diagenesis is critical for interpreting the past habitability and the fate of any organics. In this study, we aim to constrain the diagenetic history of these sediments using data from the Mastcam multispectral imager (445-1013 nm) onboard Curiosity [2]. Mastcam provides context at an outcrop-scale and its spectral range is ideal for tracking variations in Fe-bearing materials [3]. Mastcam can act as a geologic liaison from orbital data and landscape-scales to small-scale data from drill samples.

This work synthesizes Mastcam analyses during Curiosity's traverse of Sutton Island (SI) [4], Vera Rubin ridge (VRR) [5,6], and Glen Torridon (GT) [7]. We identify variable spectral signatures from Fe-bearing clays and gray to red hematite, consistent with mineralogy from XRD [8]. Clays are interpreted as products of weathering during early diagenesis [9], but evidence for later diagenesis (e.g. sulfate veins, bleached zones, and gray hematite nodules) through all regions presents with more variability [4-7]. We hypothesize that variations are due to early diagenesis in a subaerial/lacustrine environment, followed by later diagenesis during or after burial. The presence of clays in some facies within SI and GT may have inhibited late fluid flow, leading to greater organic preservation.

References: [1] Grotzinger et al. (2015) Science, 350. [2] Bell III et al. (2017) E\&SS., 4. [3] Wellington et al. (2017) Am. Min., 102. [4] Haber et al. (2020) LPSC 51, 2112. [5] Horgan et al. (2019) LPSC 50, 1424. [6] Jacob et al. LPSC 51, 1625 [7] Rudolph et al. (2020) LPSC 51, 1189. [8] Rampe et al. LPSC 50, 1126. [9] Bristow et al. (2018) Sci. Adv. 4. 